\title{
sciendo
}

\section{The Relationship Between Tactical Positioning and the Race Outcome in 800-M Running at the 2016 Olympic Games and 2017 IAAF World Championship}

\author{
by \\ Fernando González-Mohíno ${ }^{1,4}$, Jesús Santos del Cerro², Andrew Renfree ${ }^{3}$, \\ Inmaculada Yustres ${ }^{1}$, José $M^{\underline{a}}$ González-Ravé ${ }^{1}$
}

The purpose of this analysis was to quantify the probability of achieving a top-3 finishing position during 800$m$ races at a global championship, based on dispersion of the runners during the first and second laps and the difference in split times between laps. Overall race times, intermediate and finishing positions and $400 \mathrm{~m}$ split times were obtained for 43 races over $800 \mathrm{~m}$ (21 men's and 22 women's) comprising 334 individual performances, 128 of which resulted in higher positions (top-3) and 206 the remaining positions. Intermediate and final positions along with times, the dispersion of the runners during the intermediate and final splits (SS1 and SS2), as well as differences between the two split times (Dsplits) were calculated. A logistic regression model was created to determine the influence of these factors in achieving a top-3 position. The final position was most strongly associated with SS2, but also with SS1 and Dsplits. The Global Significance Test showed that the model was significant $(p<0.001)$ with a predictive ability of $91.08 \%$ and an area under the curve coefficient of 0.9598 . The values of sensitivity and specificity were $96.8 \%$ and $82.5 \%$, respectively. The model demonstrated that SS1, SS2 and Dplits explained the finishing position in the 800-m event in global championships.

Key words: behavior, performance, endurance, athletics.

\section{Introduction}

Performance analysis has developed in the last decade in order to better understand athletic performance through the use of systematic observations (Ofoghi et al., 2013). Moreover, the scientific literature has paid attention to the effects of different pacing strategies (Hanley, 2013; Thiel et al., 2012) during the finals of international track and field championships in order to explain differences in intensity distribution between successful and less successful participants. Tucker et al. (2006) described pacing strategies in middle and longdistance running events where the aim was to achieve the fastest possible finishing time.
Although pacing strategy is important to regulation of exercise intensity during a competition, we must not forget that athletes compete against direct opponents. Tactical decisions in the race such as intermediate positioning relative to other competitors or responses to opponent's behaviors affect winning chances (Smits et al., 2014). However, although athletes may have a planned pacing strategy at the beginning of an event, due to changes in the characteristics of the environment, they may decide to modify their behavior (Smits et al., 2014; St Clair Gibson et al., 2006). Indeed, a recent study found that the presence and the behavior of an opponent would affect decisions regarding

1 - University of Castilla-La Mancha, Sport Training Lab, Toledo, Spain.

2 - University of Castilla-La Mancha, Department of Statistics, Toledo, Spain.

3 - University of Worcester, Inst of Sport and Exercise Science, Henwick Grove, Worcester, UK.

4 - Facultad de Lenguas y Educación, Universidad Nebrija, Madrid, Spain. 
exercise intensity under laboratory-controlled conditions (Konings et al., 2016).

Although pacing in endurance events has been investigated previously in competitive races (Hanley, 2013, 2015; Thiel et al., 2012) and simulated races on the track (Hanon et al., 2008), understanding of pacing behavior or tactics in endurance performance is still limited (Konings et al., 2016). Pacing studies regarding middledistance events $(800 \mathrm{~m}$ or $1500 \mathrm{~m})$ have been conducted in championships (Aragón et al., 2016; Hanley and Hettinga, 2018; Renfree et al., 2014; Sandford et al., 2018) or in men's world record performances in track athletics (Tucker et al., 2006). Those studies in championships have analyzed positions and times of the athletes, but intermediate positions have been little studied (Renfree et al., 2014) and the dispersion of the runners at those intermediate positions and its influence on the final position remain unknown.

Major championships in athletics usually involve qualification rounds (heats \& semi-finals) which must be negotiated in order to qualify for the final, for which 8 places are usually available in the $800 \mathrm{~m}$ event. In heats and semi-finals depending on the event, some athletes advance to the next round by place and others as fastest losers based on finishing times. However, Hanley and Hettinga (2018) found that the vast majority of finalists of the Olympics and World Championships from 1999 to 2017 won both their heat and semi-finals, possibly demonstrating a will to win each race. Based on this finding, it can be suggested that superior athletes tend to achieve higher finishing positions in both preliminary qualifying rounds and finals showing a will to win each race instead of qualifying as faster losers. In this study, we define a 'high position' as being one of the first three finishers. Such a position is required to achieve a podium finish in finals, or typically to achieve a qualification from preliminary heats.

The 800-m middle distance running event is complex, partly because sometimes it involves in the same race two different typologies of $800 \mathrm{~m}$ runners (A - speed type, B - endurance type). The pacing strategy displayed for these runners could be different, hence, the importance of analyzing the competition is essential. In this event, the World Record performance has been characterized by progressive slowing of pace
(Tucker et al., 2006). However, in international championships the finishing position is a more important outcome that finishing time, and Renfree et al. (2014) found that tactical positioning at intermediate points (400-m and $600-\mathrm{m}$ ) of $800-$ $\mathrm{m}$ races was a strong determinant of qualification to the next round. However, this study did not take into account the dispersion of the runners at intermediate points of the $800-\mathrm{m}$ races, only the location of the runner with respect to the other opponents.

For this reason, the aim of the present analysis was to quantify the probabilities to achieve a top 3 finishing position in 800-m running races in men's and women's events at the 2016 Olympic Games and 2017 World Athletics Championship, based on the dispersion of the runners on the first and second laps, and the differences between 400-m split times.

\section{Methods}

\section{Participants}

Overall race times, intermediate and finishing positions as well as split times every 400 $\mathrm{m}$ were obtained for competitors (men and women) at the recent 2016 Olympic Games and 2017 World Athletics Championship in the 800-m event; these data are publically available on the website of the International Association of Athletics Federations (IAAF) (www.iaaf.org). Informed consent and ethical approval were not required as all data were available on the public website. The two events were top-class competitions featuring the world's best athletes at that moment. In total, 43 races of $800 \mathrm{~m}$ (21 men's and 22 women's) comprising 334 individual performances, 128 of which resulted in higher positions (top 3) and 206 the remaining positions were considered. The descriptive data related with the season's best times of all runners and results (mean time) for the races during the championships analysed are presented in Table 1.

\section{Design and Procedures}

Intermediate and final positions along with times, a standardized score of each runner in relation to the average time of the runners in that intermediate or final point (SS1 and SS2), as well as differences between the two split times (Dsplits) (independent variables) were calculated. The standardized scores of each split were calculated as follow: 
$S S=\frac{\text { individual split time }- \text { mean split time of the race }}{\text { Standard deviaton }}$

A value of 0 indicates that the individual split time and the mean split time of all the runners in that race is the same. This variable shows the dispersion of the runners during the intermediate and final splits (400 m laps). For example: the split time of five runners during the first lap are: 49.0, 49.5, 50.0, 50.5 and $51.0 \mathrm{~s}$. The average of these times is 50.0 and its standard deviation is 0.707 . The standardized score of the first runner would be $(49.0-50.0) / 0.707=1.414=$ $141.4 \%$, which would mean that this runner's time was lower than the group average over this section by 1.414 standardized points in relation to their relative dispersion. This allows to obtain a homogeneous measurement when making comparison in similar competitions.

The difference between laps was calculated by subtracting the first split time from the second split time.

\section{Statistical Analysis}

A logistic regression model (LR) was created to determine the importance of these variables in achieving a high position (dependent variable top 3 positions) in each race. This model relates the final position of each race with the explanatory variables described above (SS1, SS2 and Dsplits). The finishing position was dichotomized, assigning the first three positions a value of 1 , and the remaining positions a value of 0 .

Following that, the model was fitted using the method of maximum likelihood ( $\mathrm{R}^{2} \mathrm{McF}$ adden and $R^{2}$ Nagelkerke coefficients). Then, the ROC was a curve generated by plotting the true positive rate (TPR) against the false positive rate (FPR) at various threshold settings while the AUC was the area under the ROC curve. As a rule of thumb, a model with good predictive ability should have an AUC closer to 1 (1 is ideal) than to 0.5 . Finally, a test for the goodness of fit was carried out.

The entire model combined heats, semifinals and finals of the two competitions. We deemed it appropriate to combine male and female performances, as the model incorporates times and positions relative to other runners, without comparison between races and without taking into account absolute times.

\section{Results}

The analysis of deviance (Table 2) shows the explanatory importance of the variables in the model. The most important explanatory variable was SS2, followed by SS1, and then the difference between split times.

In relation to the estimation of the model (Table 2), the Global Significance Test demonstrated that the entire model was significant $(p<0.001)$. Analyzing the variables individually, SS1 (OR [Odd Ratio], 0.97; 95\% CI, 0.96-0.98) and SS2 (OR, 0.91; 95\% CI, 0.89-0.94) variables were significant $(p<0.001)$, although Dsplits (OR, 1.21; 95\% CI, 0.93-1.57) did not achieve our threshold for significance $(p=0.154)$.

An increase of 1 standardized point in Dsplits (meaning a reduction in the difference between split 1 and 2) would suggest a $21 \%$ increase in the probability of achieving a top three position. On the other hand, a reduction of 1 standardized score in SS1 (lower dispersion of runners) would suggest a $3 \%$ decrease in probability of achieving a top three position. However, if we did the same with the standardized score of SS2, the probability would be $9 \%$.

The model was fitted using the method of maximum likelihood, through several coefficients as $\mathrm{R}^{2}$ McFadden (66.82\%) and $\mathrm{R}^{2}$ Nagelkerke (80.05\%). This illustrates the explanatory capacity of our model. In relation to the model's predictive ability, we calculated the confusion matrix (Figure 1) with accuracy of $91.08 \%$. As observed in the ROC curve (Figure 1), the optimal probability value was 0.180 . Likewise, the optimal values of sensitivity and specificity were $96.8 \%$ and $82.5 \%$, respectively. Thus, the predictive ability of our model was excellent with an AUC coefficient of 0.9598 .

Ultimately, the Hosmer-Lemeshow test for goodness of fit was conducted. The null hypothesis was that the observed values would coincide with what was expected. The $p$ value was 0.53 , showing the great predictive ability of our LR model. Finally, we estimated the multinomial logistic model and the fit of the model was considerably less accurate than the dichotomous model. 
Table 1

Descriptive data about the races and times analysed

2016 Olympic Games

\begin{tabular}{|c|c|c|c|c|}
\hline & \multicolumn{2}{|c|}{2016 Olympic Games } & \multicolumn{2}{|c|}{$\begin{array}{l}2017 \text { World Athletics } \\
\text { Champonships }\end{array}$} \\
\hline & Men & Women & Men & Women \\
\hline Season's best (s) & $106.12 \pm 2.99$ & $120.95 \pm 3.40$ & $\begin{array}{c}103.74 \pm \\
15.19\end{array}$ & $120.04 \pm 1.97$ \\
\hline Results (s) & $106.97 \pm 2.45$ & $121.94 \pm 5.90$ & $107.15 \pm 3.42$ & $121.41 \pm 3.90$ \\
\hline
\end{tabular}

*Season's best: mean time for all runners during the season of the championship

Table 2

Estimation of logistic regression model.

\begin{tabular}{|c|c|c|c|c|c|c|c|}
\hline Continous variable & Description & Estimate & Std. Error & Odd ratio & $p$ & exp.loci & exp.upci \\
\hline Intercept (constant) & & -4.6763 & 0.8400 & 0.0093 & 0.0000 & 0.0018 & 0.0483 \\
\hline $\begin{array}{l}\text { Dsplits (Split time } 1 \text { - } \\
\text { Split time 2) }\end{array}$ & $\begin{array}{l}\text { Continous scale } \\
\text { in } \mathrm{s}\end{array}$ & 0.1906 & 0.1345 & 1.2100 & 0.1564 & 0.9296 & 1.5749 \\
\hline SS1 & $\begin{array}{l}\text { Standarized } \\
\text { score }\end{array}$ & -0.0277 & 0.0050 & 0.726 & 0.0000 & 0.9631 & 0.9823 \\
\hline SS2 & $\begin{array}{l}\text { Standarized } \\
\text { score }\end{array}$ & -0.0866 & 0.0142 & 0.9170 & 0.0000 & 0.8918 & 0.9429 \\
\hline & $\begin{array}{r}\text { Glok } \\
\text { Hosmer and }\end{array}$ & $\begin{array}{r}\text { l signific } \\
\text { emeshow } \\
R^{2} \\
R^{2} \\
R^{2}\end{array}$ & $\begin{array}{l}\text { test }=207 . \\
\text { dness-of-F } \\
\text { adden }=0.6 \\
\text {-Snell }=0.5 \\
\text { elkerke }=0 .\end{array}$ & $\begin{array}{l}783 ; p=0 . \\
\text { Test }=1.35 \\
82 \\
88 \\
005\end{array}$ & $\begin{array}{l}700 \\
7 ; p=0\end{array}$ & & \\
\hline
\end{tabular}




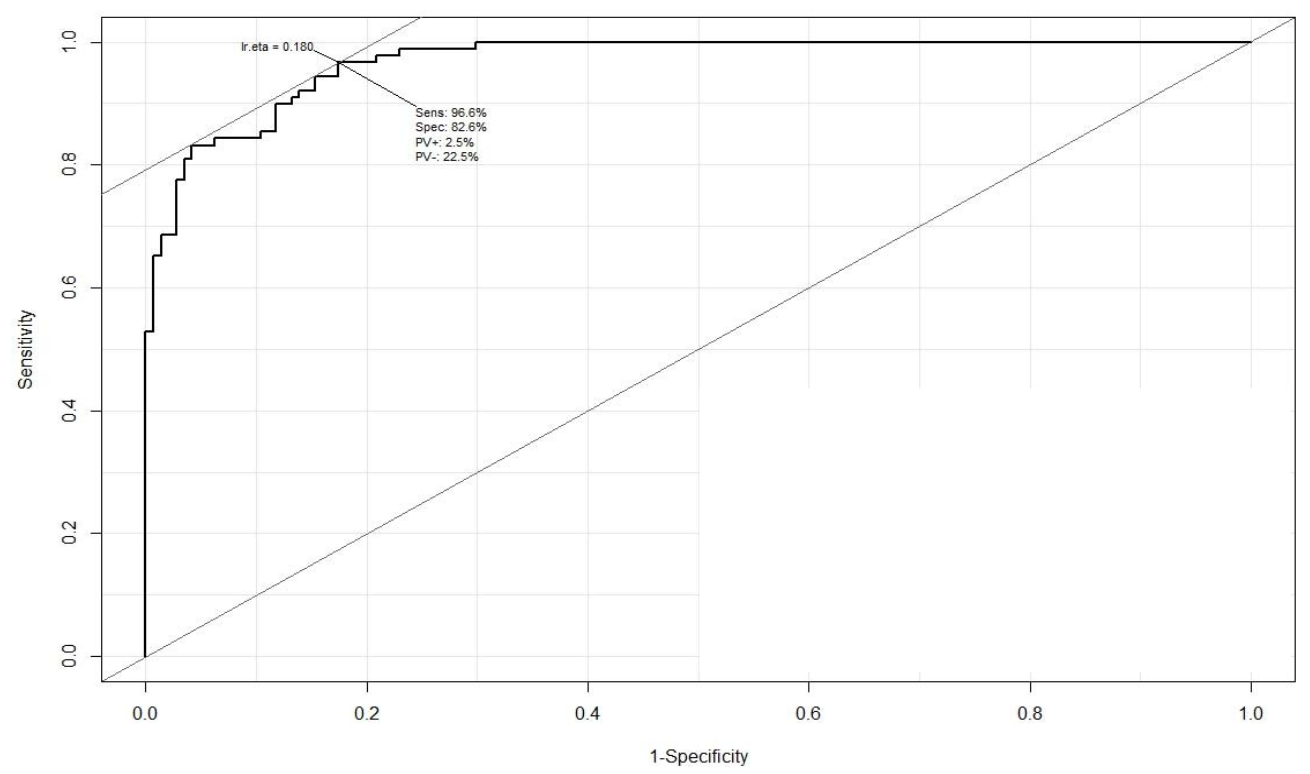

Figure 1

The ROC curve showing sensitivity and 1-specificity for prediction of the final position. AUC indicates the area under the curve.

\section{Discussion}

The main finding of this study was that the use of the standardized score of each runner on each lap to observe the dispersion between laps and the difference between lap times was an important determinant of the final position in global championships. The $800-\mathrm{m}$ event is probably one of the most difficult races in track and field, because in such a short and fast race with so many opponents, tactics are fundamental. For example, the tactical approach to positioning during the race determines the total distance covered which in turn influences the final result (Jones and Whipp, 2002). Recently, it has been shown that the position at intermediate points is a strong determinant for qualification to the next round in the 800-m event (Renfree et al., 2014). However, the data presented in the present study also demonstrate that the dispersion of the runners in each lap and the difference between lap times predict the likelihood of achieving a top three finishing position with accuracy of $91 \%$ in our LR model. Split times every 400-m were used due to the availability of data, and because the aim was to create a predictive model rather than describing pacing behavior. Nonetheless, we acknowledge the use of more frequent split times could help improve the model.

Another important finding of our study relates to the Dsplits variable. As illustrated in Table 2, the OR indicates that the reduction of $1 \mathrm{~s}$ in the difference between the second lap and the first, increases by $21 \%$ the probabilities to achieve 
higher positions. Sandals et al. (2016) reported that elite $800-\mathrm{m}$ runners used a positive pacing strategy, and the best race strategy in 800-m middle-distance running if the goal was to achieve the fastest possible finishing time, was small progressive slowing (Tucker et al., 2006) or positive pacing. However, in championships the finishing position is more important, and our results indicate that a difference in times between the second and the first split increases the probability of finishing in the top three positions. In international championships, Thiel et al. (2012) reported that runners used different pacing strategies over the same distance of running, as constant pace running in middle distance events does not occur. This means that runners adopt pacing behaviors that are, at least partially, influenced by opponents (Hettinga et al., 2017). The best athletes have the motivation to achieve a high position in heats and semi-finals regardless of the time achieved (Hanley and Hettinga, 2018), and for that reason, those athletes should choose a fast pace to expand the distance between athletes, ensuring a high position as we propose in this study. In the second lap, the dispersion between runners is more pronounced, being the most important variable in explaining the final position, because runners who finish in lower positions slow more than those who finish at the top positions. In this case, the odds ratio of SS2 indicates that the reduction of 1 standarized score results in an increase of $9 \%$ in the probability of achieving a top three position. The odds ratio of SS1 shows a smaller increase of 3\%. Although Renfree et al. (2014) found that the intermediate positions were a strong determinant of eventual high finishing positions (and progressing from preliminary rounds), this study did not consider the dispersion between runners at any point, meaning the overall position may not be particularly important if athletes are within close proximity to each other. However, if the difference between runners is considerable, the opportunity to get back close to the front of the race may be reduced. Thus, the strategic and tactical approach to the competition must take these issues into account and runners must continually adapt to changes in positions and distance between them, meaning actual behavior adopted may differ substantially from the overall strategic approach developed in advance of the race.

We acknowledge that combining male and female performance could represent a limitation of this analysis. Filipas et al. (2018) showed different tactical behavior between male and female runners in $800 \mathrm{~m}$ Diamond League running. However, we created a predictive model rather than described tactical behavior, and the times and positions were relative to each race, without comparison between races and sex. Furthermore, Filipas et al. (2018) analyzed Diamond League races, which differ from the championships races because they use pacemakers to control the speed at the early stages.

The findings of this analysis have important practical implications for athletes and coaches aiming to achieve high positions in $800 \mathrm{~m}$ races in major championships. Taking into account that previous researchers showed athletes with superior SBs were more likely to progress from preliminary rounds, and that intermediate positions were determinants of qualification from preliminary rounds (Renfree et al., 2014), we suggest that the dispersion of the runners at those intermediate points and the difference between split times are also important determinants of the likelihood of achieving a top three finishing position. Normally, superior runners tend to adopt higher positions in races to ensure the qualification or medals (Hanley and Hettinga, 2018), so that if the better runners want to maximize likelihood of qualification or medals, it would be important to increase the dispersion between runners at each intermediate points, because the probabilities of success would increase. On the contrary, the runners situated in the lower positions should assume locating close to the front of the race to increase the probabilities of success. An application of this analysis is that coaches should encourage their runners to assume higher race positions and also decrease the distance between them, because it is decisive in reaching the final position. 


\section{References}

Aragón S, Lapresa D, Arana J, Anguera MT, Garzón B. Tactical behaviour of winning athletes in major championship 1500-m and 5000-m track finals. Eur J Sport Sci, 2016; 16(3): 279-286

Filipas L, Ballati NE, Bonato M, La Torre A, Piacentini MF. Elite male and female 800-m runners display different pacing strategies during seasons best performances. Int J Sports Physiol Perfom, 2018; 10: 1-20

Hanley B. An analysis of pacing profiles of world class race walkers. Int J Sports Physiol Perfom, 2013; 8: 435441

Hanley B. Pacing profiles and pack running at the IAAF World Half Marathon Championships. J Sports Sci, 2015; 33(11): 1189-1195

Hanley B, Hettinga FJ. Champions are racers, not pacers: an analysis of qualification patterns of Olympic and IAAF World Championship middle distance runners. J Sports Sci, 2018; 36(22): 2614-2620

Hanon C, Leveque JM, Thomas C, Vivier L. Pacing strategy and $\mathrm{VO}_{2}$ kinetics during a 1500-m race. Int J Sports Med, 2008; 29(3): 206-211

Hettinga FJ, Konings MJ, Pepping GJ. The science of racing against opponents: Affordance competition and the regulation of exercise intensity in head-to-head competition. Front Physiol, 2017; 8: 118

Jones AM, Whipp BJ. Bioenergetic constraints on tactical decision making in middle distance running. $\mathrm{Br} \mathrm{J}$ Sports Med, 2002; 36(2): 102-104

Konings MJ, Schoenmakers PP, Walker AJ, Hettinga FJ. The behavior of an opponent alters pacing decisions in 4-km cycling time trials. Physiol Behav, 2016; 158: 1-5

Ofoghi B, Zeleznikow J, MacMahon C, Raab M. Data mining in elite sports: A review and a framework. Meas Phys Edu Exerc Sci, 2013; 17(3): 171-186

Renfree A, Mytton GJ, Skorski S, Gibson AS. Tactical considerations in the middle-distance running events at the 2012 Olympic Games: a case study. Int J Sports Physiol Perfom, 2014; 9(2): 362-364

Sandals LE, Wood DM, Draper SB, James DV. Influence of pacing strategy on oxygen uptake during treadmill middle-distance running. Int J Sports Med, 2016; 27(1): 37-42

Sandford GN, Pearson S, Allen SV, Malcata RM, Kilding AE, Ross A, Laursen PB. Tactical behaviors in men's 800-m Olympic Championship Medalists: A changing of the guard. Int J Sports Physiol Perfom, 2018; 13: 246-249

Smits BL, Pepping GJ, Hettinga FJ. Pacing and decision making in sport and exercise: The roles of perception and action in the regulation of exercise intensity. Sports Med, 2014; 44(6): 763-775

St Gibson AC, Lambert EV, Rauch LH, Tucker R, Baden DA, Foster C, Noakes TD. The role of information processing between the brain and peripheral physiological systems in pacing and perception of effort. Sports Med, 2006; 36(8): 705-722

Thiel C, Foster C, Banzer W, de Koning J. Pacing in Olympic track races: Competitive tactics versus best performance strategy. J Sports Sci, 2012; 30(11): 1107-1115

Tucker R, Lambert MI, Noakes TD. An analysis of pacing strategies during men's world-record performances in track athletics. Int J Sports Physiol Perfom, 2006; 1(3): 233-245

\section{Corresponding author:}

\section{José Ma González-Ravé}

Faculty of Sport Sciences

Avenida Carlos III s/n

45071 Toledo (Spain)

Telephone: 0034925268800 ext (5519)

Fax: 0034925268846

E-mail: josemaria.gonzalez@uclm.es 